fairly represented that of the meeting, and it was supported by Prof. Schäfer, F.R.S., Prof. Gotch, F.R.S., and others.

The individual papers were perhaps fewer than is usually the case. Prof. Sherrington, F.R.S., added another to the series of communications on the coordination of reflex muscular movements in the spinal animal which has added so much to the interest of the British Association meetings in the last few years. Very beautiful examples were shown of graded reflex movements which took place in response to graded stimuli. His experiments throw a good deal of light upon the action of strychnine. This drug appears to cause an exaggeration of the rebound which takes place normally after reflex inhibition. The inhibition may be re-established by giving chloroform. Two practical points were brought out:-(I) that in many cases the physiological units of musculature do not correspond to the anatomical ones; and (2) that there is a portion of the gluteus maximus muscle which does not respond either to ordinary reflex stimulation or to strychnine.

Papers on the physiology of nerve were read by Dr. Alcock and Prof. Macdonald. Interesting in themselves, these communications were rendered doubly so by the fact that their writers take a diametrically opposite view of the nature of the nervous impulse.

Three reports were presented by committees; they dealt, respectively, with the metabolic balance sheet of the in dividual tissues, the ductless glands, and the effect of climate upon health. Their work evoked more interest than usual. The afternoon was spent in discussing the report of the committee of which Sir Lauder Brunton is chairman, and which is a very strong one. It has worked very hard in its efforts to produce a schedule for the collection of the necessary data for the comparison of the climatic conditions of various localities with the diseases which are prevalent in them. Along another line the committee has been greatly strengthened by the active interest of Prof. Zuntz, who came over to Leicester and gave an account of the work which is now being inaugurated in Berlin.

Prof. Zuntz is continuing the work which he and his collaborators carried on in the high Alps, and at the present time two travellers, Drs. Schilling and Jaffé, are making a corresponding set of observations upon themselves in Togo. It will be of great interest to compare the effects of hot climate with the positive results which were obtained upon the high Alps. J. BARCROFT.

\section{THE KINGSTON EARTHQUAKE.}

THE official report on thy Kingston earthquake, of January 14 last, by Hall, contains, in addition to the customary conpriation of accounts of time, duration on volene or the shock, some interesting records of/the leculigh behaviour of the sea on the north coast of idy d. At Annotto Bay and Port Maria the sea receded, about three or four minutes before the shock at Port Maria, at about the same time after it according to the account from Annotto Bay, the amount of the recession being equivalent to a vertical fall of from 12 feet to 20 feet; after the shock the sea returned in a wave which swept up the shore to 6 feet or 8 feet above its normal level. This phenomenon was only recorded at the two localities mentioned, a fact which points to its being probably due to movement of the land rather than to a sea wave. At the Kempshot Observatory, St. James, the masonry pier of the transit instrument, resting on solid rock, was found to have been disturbed, so that the west end of the axis was $32^{\prime \prime}$ higher than the east end. In Kingston Harbour subsidence of the land was noticed along the shore-line, of more than 24 feet in places, but this appears to have been due to the shaking down of loose accumulations of recent deposits, as there is no indication of a permanent change of level in the centre of the harbour or on land except near the shore-line.

Beside the official report, we have received from Prof. Carmody, of Trinidad, a series of photographs taken in Kingston on the second and third day after the earthquake. Two of these are reproduced, which show the character of

No. 1977 , voL. 767 the damage done; this was greatest in the case of walls facing east, those facing north or south being generally uninjured. A noteworthy peculiarity was the fact that arched openings seem to have withstood the shock while

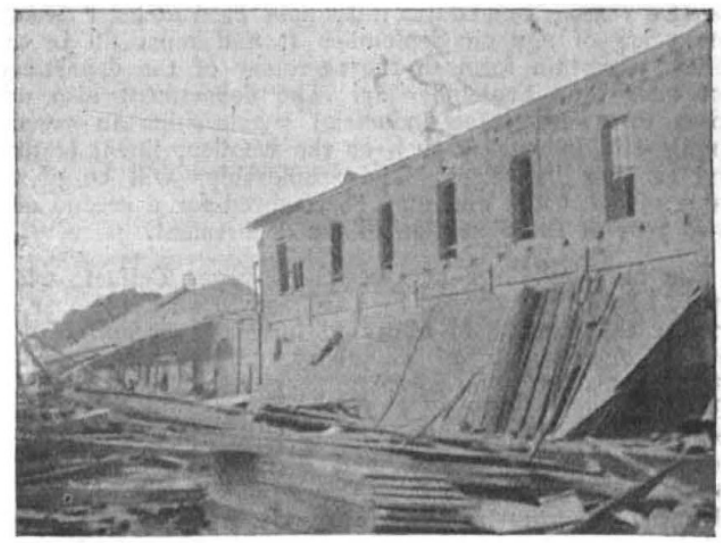

FIG. I.-Railway station wall facing south.

the rest of the wall was destroyed; as there is no form of construction less suited than the arch to withstand the strains set up by an earthquake shock, this can only be

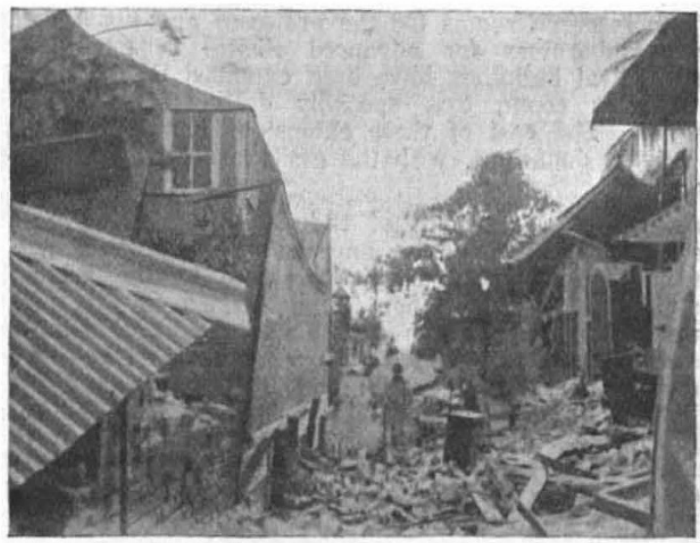

FIG. 2.-Typical north and south narrow street.

ascribed to the badness of material used for building, the arches having stood owing to the necessity for using better material and more skilled workmanship in their construction.

\section{UNIVERSITY AND EDUCATIONAL INTELLIGENCE.}

$\mathrm{By}$ the will of the fate Mr. A. H. Blount; lord of the manor of Orletoy. Aereford, who died in London on June 17 , Yale Ufinersity will receive a bequest the value of which, after pqyment of duties, \&c., will amount to about $80,000 l$

THE new session of Birkbeck College, London, will be opened on Monday, September 30, when an address will be given by Mr. G. G. Chisholm. The laboratories will afterwards be open inspection, and demonstrations will be given. Thero yrill be an annual exhibition of students' works on Friday, Saturday, and Monday, September 27, 28 , and 30 .

THE Department of Agriculture and Technical Instruction for Ireland will next month, award not more than three commercial cholarships to young men having a 